\title{
Adenocarcinoma arising from cervical esophageal gastric inlet patch
}

\author{
Saad Ajmal, MD, John S. Young, MD, and Thomas Ng, MD
}

\begin{abstract}
A 57-year-old man with symptoms of reflux underwent upper endoscopy, with the finding of a $3-\mathrm{cm}$ polypoid mass at 19 to $22 \mathrm{~cm}$ measured from the incisors occupying close to one third of the esophageal circumference (Figure 1). It was estimated that there was a distance of 3.5 to $4 \mathrm{~cm}$ from the upper esophageal sphincter to the top of the mass. The mass was associated with a patch of what appeared to be ectopic gastric-type mucosa in the cervical esophagus. Biopsy of this patch at $18 \mathrm{~cm}$ showed oxyntic type gastric mucosa with focal dilated glands, consistent with an inlet patch. Biopsy of the mass showed adenocarcinoma, which was at least intramucosal because deeper invasion could not be excluded. On endoscopic ultrasonography, the mass was staged at T2N0 with involvement of the muscularis propria. Positron emission tomographic scan showed the mass to be intensely avid, but without nodal or distal metastasis (Figure 2). The patient underwent curative resection by 3-incision esophagectomy, with reconstruction by colon interposition. Pathology revealed moderately differentiated
\end{abstract}

From the Department of Surgery, Warren Alpert Medical School of Brown University, Providence, RI.

Disclosures: Author have nothing to disclose with regard to commercial support.

Received for publication March 25, 2015; accepted for publication March 28, 2015; available ahead of print April 22, 2015.

Address for reprints: Thomas Ng, MD, 2 Dudley St, Suite 470, Providence, RI 02905

(E-mail: tng@usasurg.org).

J Thorac Cardiovasc Surg 2015;149:1664-5

$0022-5223 / \$ 36.00$

Copyright (C) 2015 by The American Association for Thoracic Surgery

http://dx.doi.org/10.1016/j.jtcvs.2015.03.050

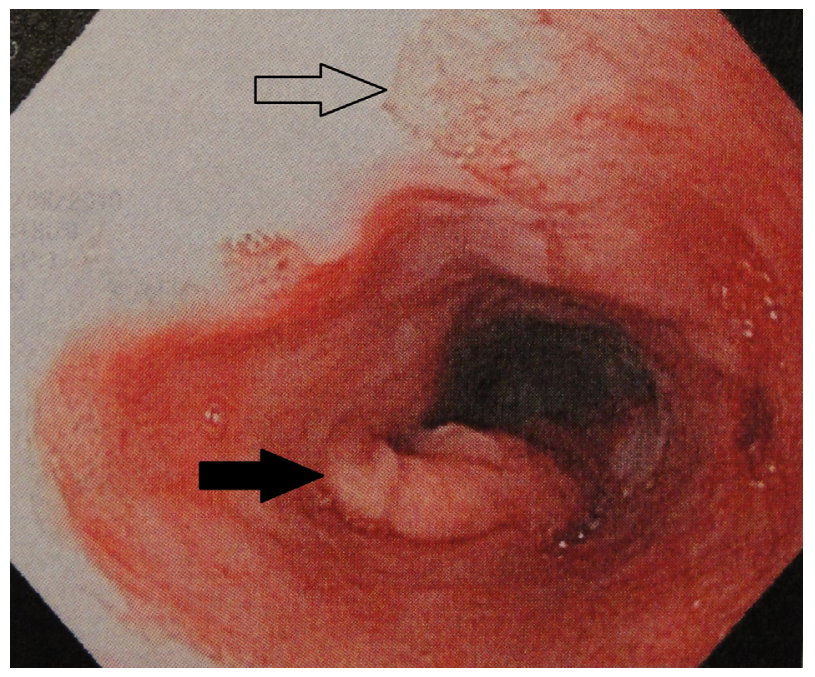

FIGURE 1. Upper endoscopy reveals a cervical esophageal polypoid mass arising from inlet patch. Solid arrow points to the polypoid mass. Open arrow points to the transition line between the ectopic gastric mucosa and the normal squamous mucosa.

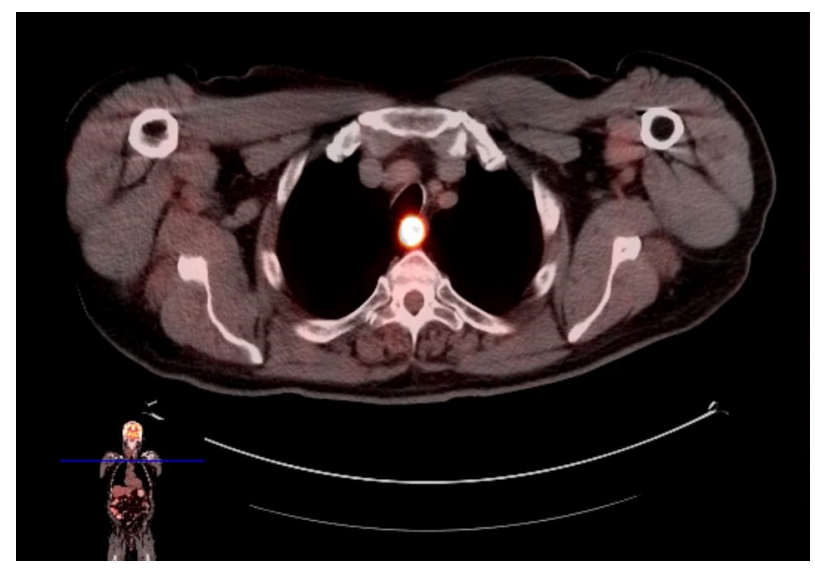

FIGURE 2. Positron emission tomography shows the cervical esophageal mass to be intensely avid but without nodal or distal metastasis.

to well-differentiated adenocarcinoma of the cervical esophagus, invading the submucosa, arising from ectopic gastric mucosa (a cervical inlet patch), with margins and 24 lymph nodes free of malignancy (Figure 3). Final pathologic stage was T1bN0.

Heterotopic gastric mucosa found in the proximal esophagus is given the term cervical inlet patch. A thorough review of this topic was recently published by Chong. ${ }^{1}$ The pathogenesis of the cervical inlet patch is considered to be congenital, although acquired etiologies have also been proposed. The prevalence varies from less than $1 \%$ to $14 \%$ in published endoscopic studies. Most inlet patches are asymptomatic and are detected coincidentally during endoscopy, when other gastrointestinal complaints are being investigated. If an inlet patch is symptomatic, the most commonly associated symptom is that of laryngopharyngeal reflux. Although rare, dysplasia and malignancy

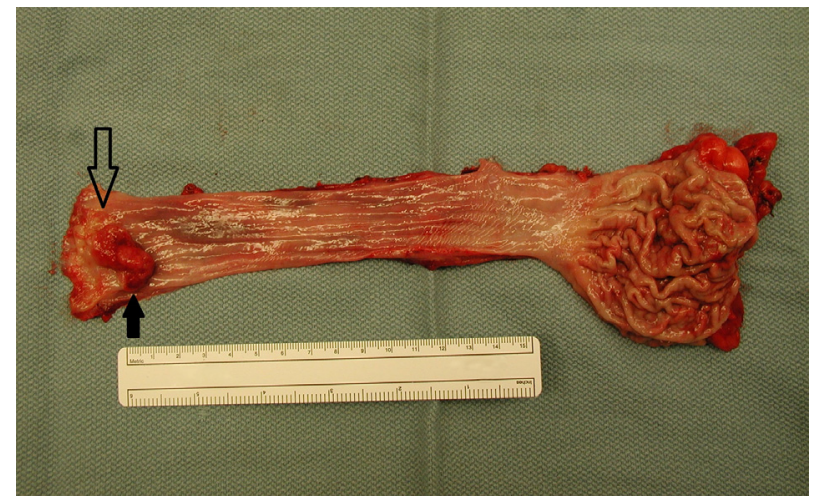

FIGURE 3. Gross specimen of the resected esophagus and proximal stomach. Solid arrow points to the polypoid mass arising from cervical inlet patch. Open arrow points to the transition line between the ectopic gastric mucosa and the normal squamous mucosa. 
arising from cervical inlet patch have been reported. The incidence of adenocarcinoma arising from cervical inlet patch is reported to be $1.5 \%$ or less.

In summary, we illustrate a patient with esophageal adenocarcinoma arising from cervical gastric inlet patch. We stress the importance of careful and thorough examination of this difficult area during any upper endoscopy. If inlet patch is found, biopsies should be obtained and endoscopic surveillance should be considered because of the possibility of the inlet patch progressing to carcinoma.

\section{Reference}

1. Chong VH. Clinical significance of heterotopic gastric mucosal patch of the proximal esophagus. World J Gastroenterol. 2013;19:331-8. 